\title{
Behaviors of Crystallization for Osmotic Pressure under Microwave Irradiation
}

\author{
Ryosuke Nakata, Yusuke Asakuma* \\ Department of Mechanical and System Engineering, University of Hyogo, Kobe, Japan \\ Email: asakuma@eng.u-hyogo.ac.jp
}

Received 14 October 2014; revised 15 November 2014; accepted 15 December 2014

Copyright $(02015$ by authors and Scientific Research Publishing Inc.

This work is licensed under the Creative Commons Attribution International License (CC BY). http://creativecommons.org/licenses/by/4.0/

(c) (i) Open Access

\begin{abstract}
We studied chemical garden in order to investigate precipitation behavior for osmotic pressure under microwave irradiation. The salt concentration and microwave irradiation power were varied. Microwave irradiation induced release of osmotic pressure and change of precipitation pattern because polar molecules vibrate and rotate in an electromagnetic field. For example, the width of precipitation increased and the number of rapture of the membrane decreased due to the release of osmotic pressure by the irradiation. Accordingly, microwave irradiation accelerated the diffusion of ionic molecules through the membrane.
\end{abstract}

\section{Keywords}

Microwave, In-Situ Observation, Osmotic Pressure

\section{Introduction}

Chemical garden for osmotic pressure forms attractive and unique tree-like patterns. The hollow tubes of basic chemical garden structure are formed when the precipitation reaction takes place at the interface between two different solutions. Precipitation from a concentrated salt solution becomes semipermeable colloidal membrane. Moreover, the growth rate pattern depends on the salt kinds and the concentration of sodium silicate $\left(\mathrm{Na}_{2} \mathrm{SiO}_{3}\right.$; water glass) in aqueous solution. Salt continues to dissolve into the solution inside the membrane and the higher osmic pressure causes the rupture of the membrane wall and jet fluid into the surrounding solution. This tubular fiber develops at the point. The morphological pattern is scientifically interesting because such pattern formation frequently inspires microstructural design in materials science [1]-[4]. However, the mechanism of chemical garden has not been clear because of the nonlinearity. In this study, we tried to control such complex pattern by outside fields.

\footnotetext{
${ }^{*}$ Corresponding author.
} 
Microwave irradiation may be helpful in this context. Microwave irradiation has recently been a very active research due to the many advantages of nonthermal effects such as reaction promotion, nucleation induction, and diffusion facilitated by the molecular vibration of polar molecules [5] [6]. We hypothesized that the precipitation reaction and diffusion characteristics through semipermeable membrane of chemical garden could be modulated or explained via various microwave properties. In addition, precipitation of chemical garden may suggest a new application of microwave irradiation and suitable operating conditions for highly functional inorganic materials of hollow tubes. The concentration of aqueous solution is essential for solving the diffusion and precipitation challenges of chemical garden phenomena [1]. In this study, we varied the concentration and microwave power to understand the microwave effect. We used a microwave reactor equipped with an in-situ observation system to capture the dynamic growth behavior of the tree-like pattern.

\section{Experimental}

Chemical garden behavior, which is crystal growth like a plant by release of osmotic pressure, is performed by addition of copper sulfate $\left(\mathrm{CuSO}_{4}\right)$ to an aqueous solution of sodium silicate $\left(\mathrm{NaSiO}_{3}\right.$; water glass) because copper silicates are insoluble in water and are colored.

First, grain of copper sulfate is placed on bottom of thin cell, which consists of three acryl resin layers as shown in Figure 1(a). Thickness of center and sides of the cell, are 2 and $1 \mathrm{~mm}$, respectively. The grain size is smaller than thickness of the width. Sodium silicate aqueous solution listed in Table 1, is poured into the cell. Examples of chemical garden are shown in Figure 1(b) and Figure 1(c). Tree like pattern is formed from the bottom to the top.

Temperature is important factor for the precipitation. We used two different methods, microwave irradiation (MW) and conventional heating (thermostatic bath, $\mathrm{CH}$ ) for maintaining solution temperature. We measured the pattern for two heating methods.

A. Microwave heating

Figure 2 shows a tube-guide microwave reactor (Shikoku Instrumentation), which is specially designed for preventing microwave leakage and equipped with a microscope camera (Sigma Koki, Model SK-TC202USBAT) for in-situ observation [5]-[7]. Cell containing the solution of chemical garden is placed at the center of the reactor. Direction of thin cell is parallel to the side and the pattern is captured through the side of the reactor, with the fixed microscope. Immediately after putting on the cell, microwave was irradiated for $20 \mathrm{~min}$. We measured the growth rate of the pattern, which is defines as time for the growth of $3 \mathrm{~mm}$ length, the width and the number of ruptures through the movie. And width is measured by every $1 \mathrm{~mm}$. Moreover, the rupture of membrane for $30 \mathrm{~min}$ is counted. Average values of six crystals for growth rate, width and the number of rup-

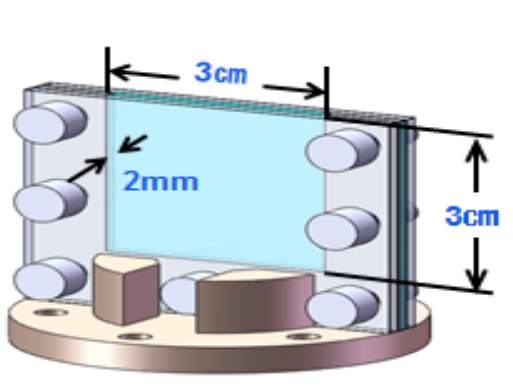

(a)

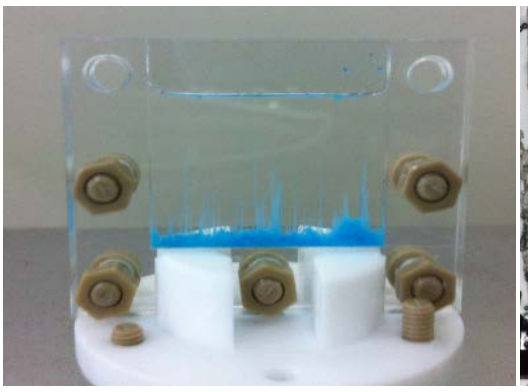

(b)

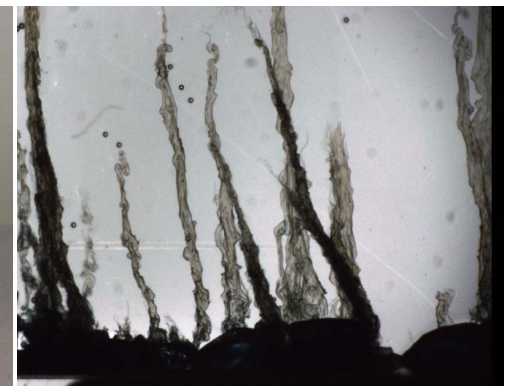

(c)

Figure 1. Cell for observation of chemical garden. (a) Cell; (b) Chemical garden in cell; (c) Enlarge view of chemial garden $(6 \mathrm{~mm} \times 8 \mathrm{~mm})$.

Table 1. Experimental conditions.

\begin{tabular}{ccc}
\hline $\mathrm{Na}_{2} \mathrm{SiO}_{3}$ conc. [w\%] & MW output [W] & Temperature of bath [ $\left.{ }^{\circ} \mathrm{C}\right]$ of $\mathrm{CH}$ \\
\hline 18 & 21 & 20 \\
20 & 22.5 & 40 \\
22 & & \\
24 & & \\
\hline
\end{tabular}




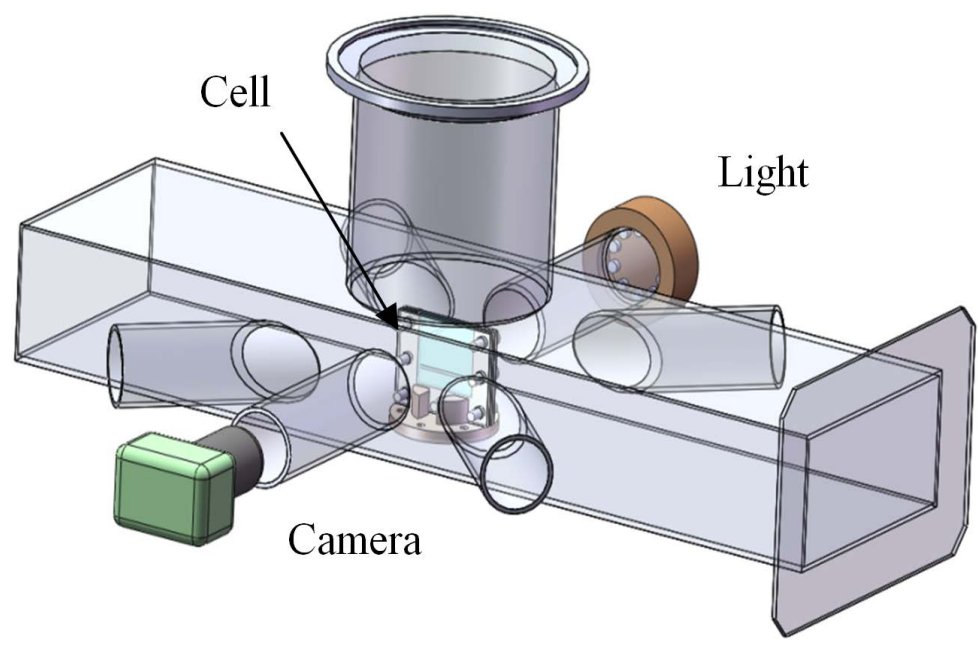

Figure 2. Microwave reactor for observation of chemical garden.

ture are calculated. These approaches enable dynamic evaluation of chemical garden with respect to microwave irradiation. After $20 \mathrm{~min}$, we measured the final temperature with an optical fiber (Anritsu Meter) because the solution temperature increases under irradiation.

B. Conventional heating

We used thermostatic bath to maintain the solution temperature. The bath temperature was same with the final temperature observed in the microwave experiment. The cell is immersed into the bath, and movie of the pattern is captured after 20 min with the microscope camera.

\section{Results and Discussion}

$\mathrm{CuSO}_{4}$ starts to dissolve in the aqueous solution after the seed crystals contact with the solution. Insoluble copper silicate immediately forms by a double decomposition reaction (anion metathesis reaction). This copper silicate is a semipermeable membrane. Because the ionic strength of the copper solution inside the membrane is higher than the sodium silicate solution, the osmotic pressure increases within the membrane. Water in the sodium silicate solution is drawn osmotically from outside into the membrane, in the meanwhile dissolution of seed crystal continues. Balance between the dissolution and the entry of water under osmotic pressure causes a rupture around tip of the membrane, and new membrane forms at the rupture points by the reaction of the copper cations and silicate anions. The crystals relatively grow upwards since the pressure at the bottom of the cell is higher than the pressure closer to the top. In this way, the growth continues in the cell and the shape looks like colored plants as shown in Figure 1(b). Generally, the position and time of rupture cannot be predicted and controlled.

Figure 3 shows growth rate of chemical garden with and without microwave for different concentration of sodium silicate. Solid and unfilled symbols indicate MW and CH conditions, respectively. Growth rate becomes higher when temperature is higher. However, effect of microwave irradiation, that is, the difference at the same temperature between $\mathrm{MW}$ and $\mathrm{CH}$, is not clear.

Figure 4 shows width of chemical garden with and without microwave for different sodium silicate. The width increased with the concentration because much sodium near the interface is supplied. Moreover, the width became wider when temperature becomes higher. On the other hand, microwave effect was observed for the width at the same temperature condition. It became a little wider by microwave irradiation. The diffusion of water molecule thorough the membrane is accelerated by molecular rotation of microwave irradiation [8] [9]. Accordingly, the diffusion causes the lower concentration of copper sulfate near the interface and slower release of osmotic pressure.

Figure 5 shows the number of ruptures for chemical garden with and without microwave for different sodium silicate. The number of ruptures decreases by microwave irradiation. In case of MW, rupture happened only around the time after pouring the solution into the cell. It means that osmotic pressure is gradually released due 


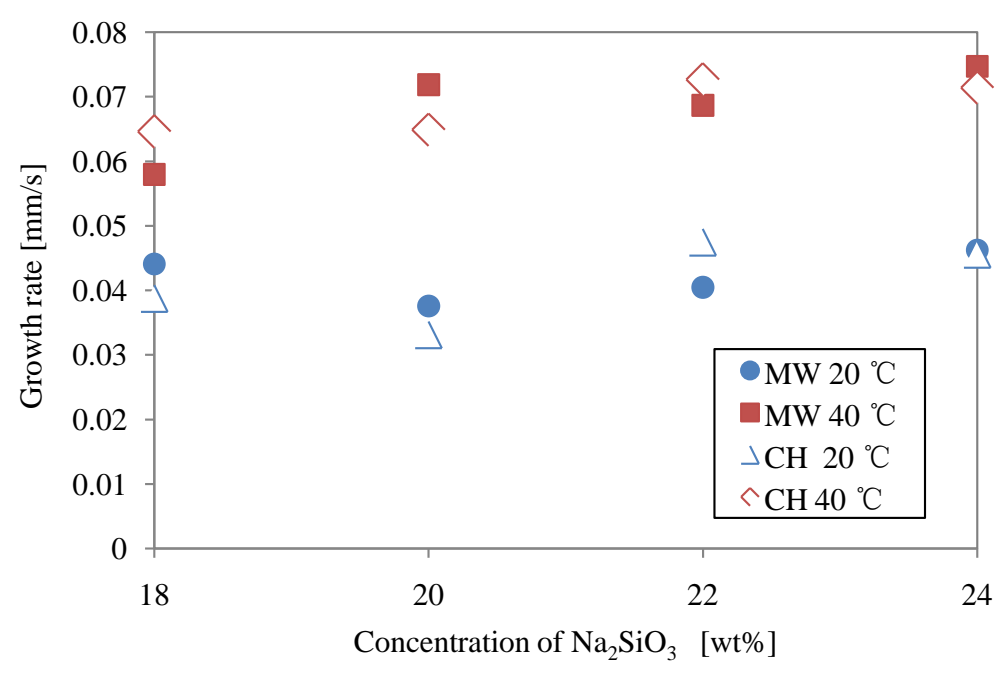

Figure 3. Growth rate of chemical garden for $\mathrm{Na}_{2} \mathrm{SiO}_{3}$ concentration with and without microwave.

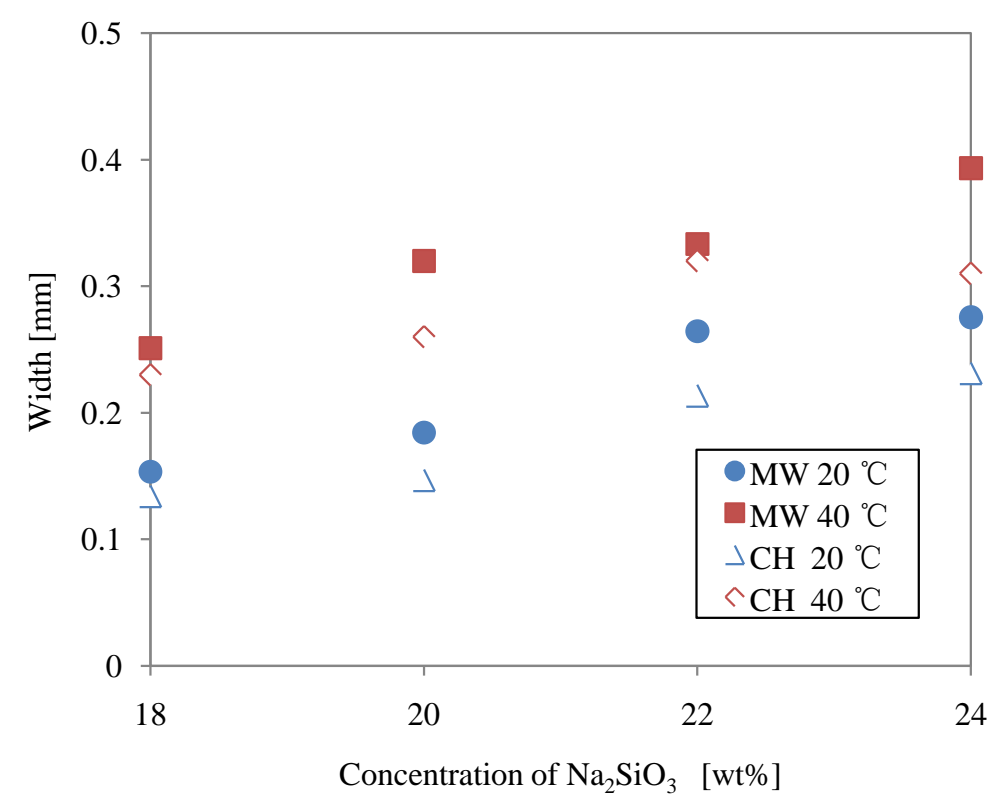

Figure 4. Width of chemical garden for $\mathrm{Na}_{2} \mathrm{SiO}_{3}$ concentration with and without microwave.

to the water molecule entry into the membrane by the irradiation, and the rupture does not happen anymore after initial rupture. Particularly, condition of higher irradiation, single rupture is observed.

Figure 6 show examples of microscope photos around tip of chemical garden with and without microwave. There are several characteristics between two heating methods. In case of no microwave, the membrane is formed perfectly, and the interface between two liquids is clear. Pattern by multiple ruptures is disordered like tree because jet flows of the solution are ejected. Consequently, the higher osmic pressure by dissolution of seed crystal and the lower pressure after the rupture repeat irregularly for the time and the position. Crystal grows up when osmotic pressure is over the limit values. The rupture will happen near thin wall of the membrane, which is pale colored in photos. According, border of membrane obtained as quick precipitation becomes darker.

On the other hand, behavior under the irradiation is different with conventional heating. For example, the border of straight membrane is not clear by microwave irradiation. Moreover, weak jet flow continues without closing the tip due to higher diffusion of water through the membrane. Accordingly, osmotic pressure is gradu- 


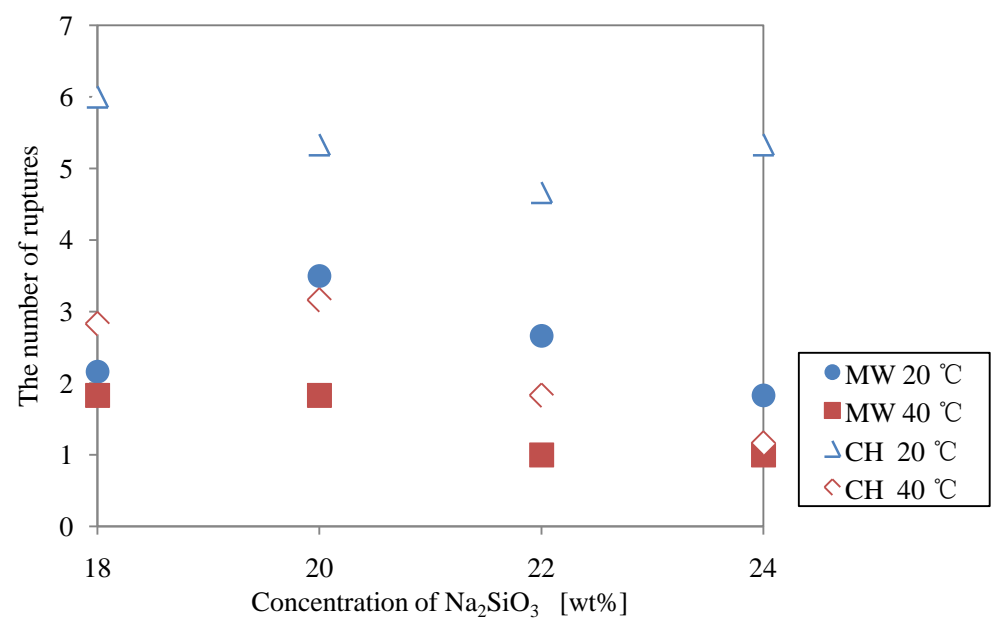

Figure 5. Number of ruptures for chemical garden for $\mathrm{Na}_{2} \mathrm{SiO}_{3}$ concentration with and without microwave.

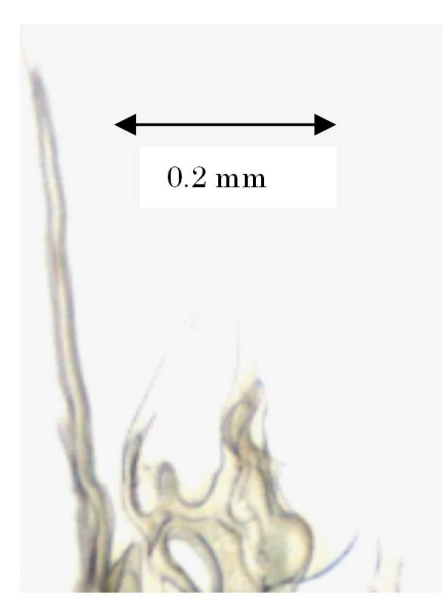

After $13 \mathrm{~s}$

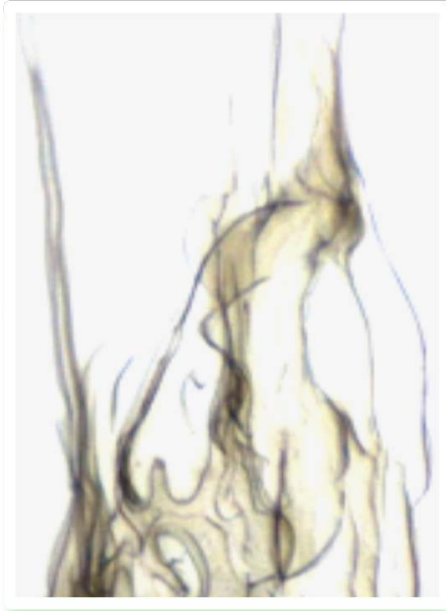

(a)
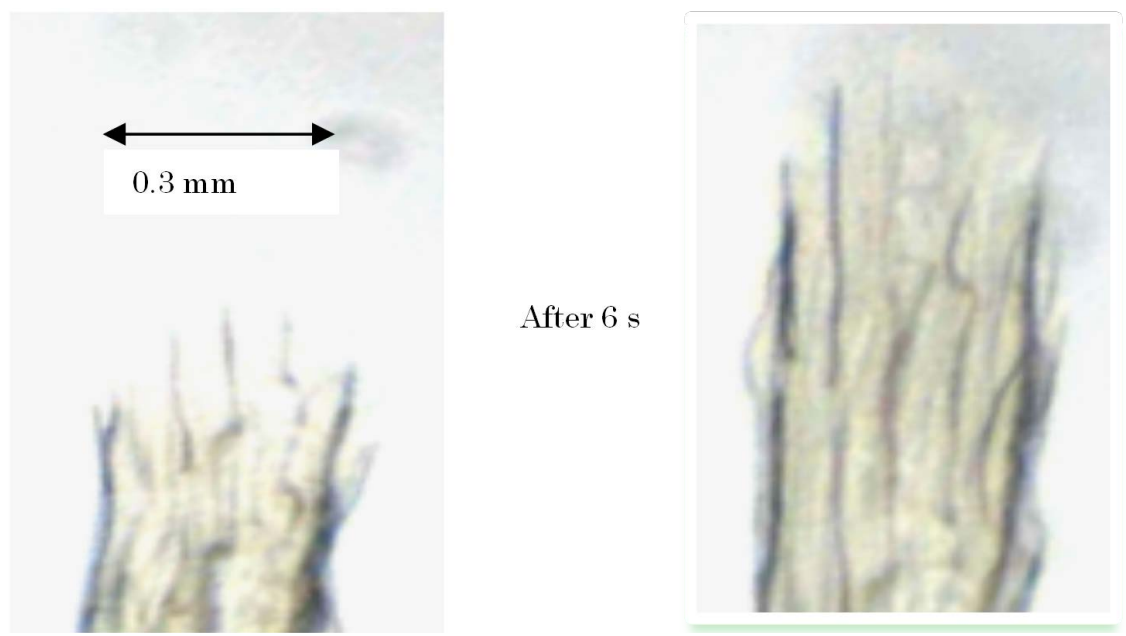

(b)

Figure 6. Microscope photos around tip of crystal with and without microwave (18 w\%). (a) Without microwave; (b) With microwave. 
ally released and condition of slower precipitation is achieved due to the smaller number of the rupture. The microwave irradiation, which prevents the rupture for osmotic pressure, can modulate the molecular diffusion and manifestation of complex patterns for chemical garden. Finally, the irradiation may be a useful tool in other fine-scale, nonequilibrium self-organization processes for nonlinear precipitation.

\section{Conclusion}

In this study, the mechanism of the crystal growth for chemical garden was investigated to clarify the osmotic pressure and the diffusion problem through the membrane under microwave irradiation. Effect of microwave on the number of the ruptures for the $\mathrm{NaSiO}_{3}$ concentration, which is the release of the osmotic pressure, is interesting. Although crystal growth rates with and without microwave irradiation at the same temperature condition are almost same, the number of ruptures under microwave irradiation becomes smaller. On the other hand, the osmotic pressure becomes gradually smaller due to the higher diffusion of water molecule by the irradiation. Although the rupture behavior is decided by the balance between water molecule entry through the membrane and dissolution of seed crystal, unstable and explosive release of the osmotic pressure was avoidable by the irradiation.

\section{References}

[1] Cartwright, J.H.E., García-Ruiz, J.M., Novella, M.L. and Otálora, F. (2002) Formation of Chemical Gardens. Journal of Colloid and Interface Science, 256, 351-359. http://dx.doi.org/10.1006/jcis.2002.8620

[2] Pratama, F.S., Robinson, H.F. and Pagano, J.J. (2011) Spatially Resolved Analysis of Calcium-Silica Tubes in Reverse Chemical Gardens. Colloids and Surfaces A: Physicochemical and Engineering Aspects, 389, 127-133. http://dx.doi.org/10.1016/j.colsurfa.2011.08.041

[3] Bormashenko, E., Bormashenko, Y., Stanevsky, O. and Pogreb, R. (2006) Evolution of Chemical Gardens in Aqueous Solutions of Polymers. Chemical Physics Letters, 417, 341-344. http://dx.doi.org/10.1016/j.cplett.2005.10.049

[4] Barge, L.M., Doloboff, I.J., White, L.M., Stucky, G.D., Russell, M.J. and Kanik, I. (2011) Characterization of IronPhosphate-Silicate Chemical Garden Structures. Langmuir, 28, 3714-3721. http://dx.doi.org/10.1021/la203727g

[5] Aaskuma, Y., Murakami, Y. and Konishi, M. (2014) Anti-Solvent Effect of Crystallization by Feeding Ethanol under Microwave Radiation. Crystal Research and Technology, 49, 129-134. http://dx.doi.org/10.1002/crat.201300327

[6] Asakuma, Y. and Miura, M. (2014) Effect of Microwave Radiation on Diffusion Behavior of Anti-Solvent during Crystallization. Journal of Crystal Growth, 402, 32-36. http://dx.doi.org/10.1016/j.jcrysgro.2014.04.031

[7] Parmar, H., Kanazawa, Y., Asada, M., Asakuma, Y., Phan, C., Pareek, V. and Evans, G. (2014) Influence of Microwave on Water Surface Tension. Langmuir, 30, 9875-9879. http://dx.doi.org/10.1021/la5019218

[8] Nakai, Y., Tsujita, Y. and Yoshimizu, H. (2002) Control of Gas Permeability for Cellulose Acetate Membrane by Microwave Irradiation. Desalination, 145, 375-377. http://dx.doi.org/10.1016/S0011-9164(02)00439-3

[9] Nakai, Y., Yoshimizu, H. and Tsujita, Y. (2005) Enhanced Gas Permeability of Cellulose Acetate Membranes under Microwave Irradiation. Journal of Membrane Science, 256, 72-77. 
Scientific Research Publishing (SCIRP) is one of the largest Open Access journal publishers. It is currently publishing more than 200 open access, online, peer-reviewed journals covering a wide range of academic disciplines. SCIRP serves the worldwide academic communities and contributes to the progress and application of science with its publication.

Other selected journals from SCIRP are listed as below. Submit your manuscript to us via either submit@scirp.org or Online Submission Portal.
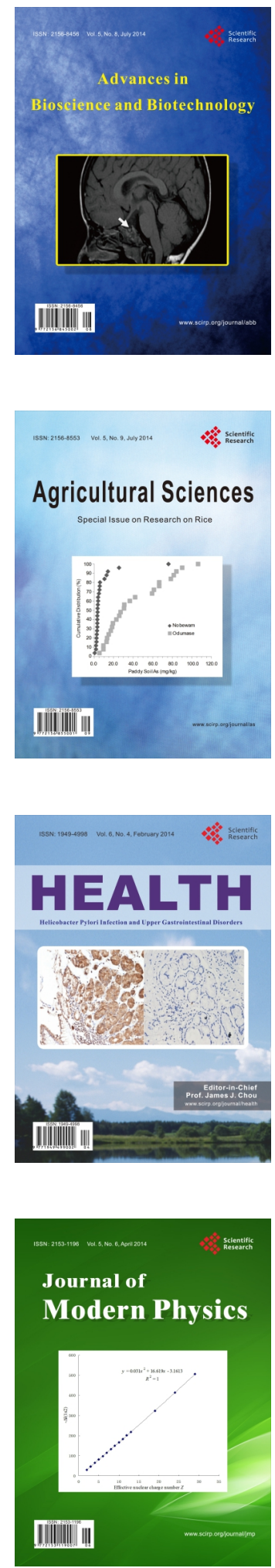
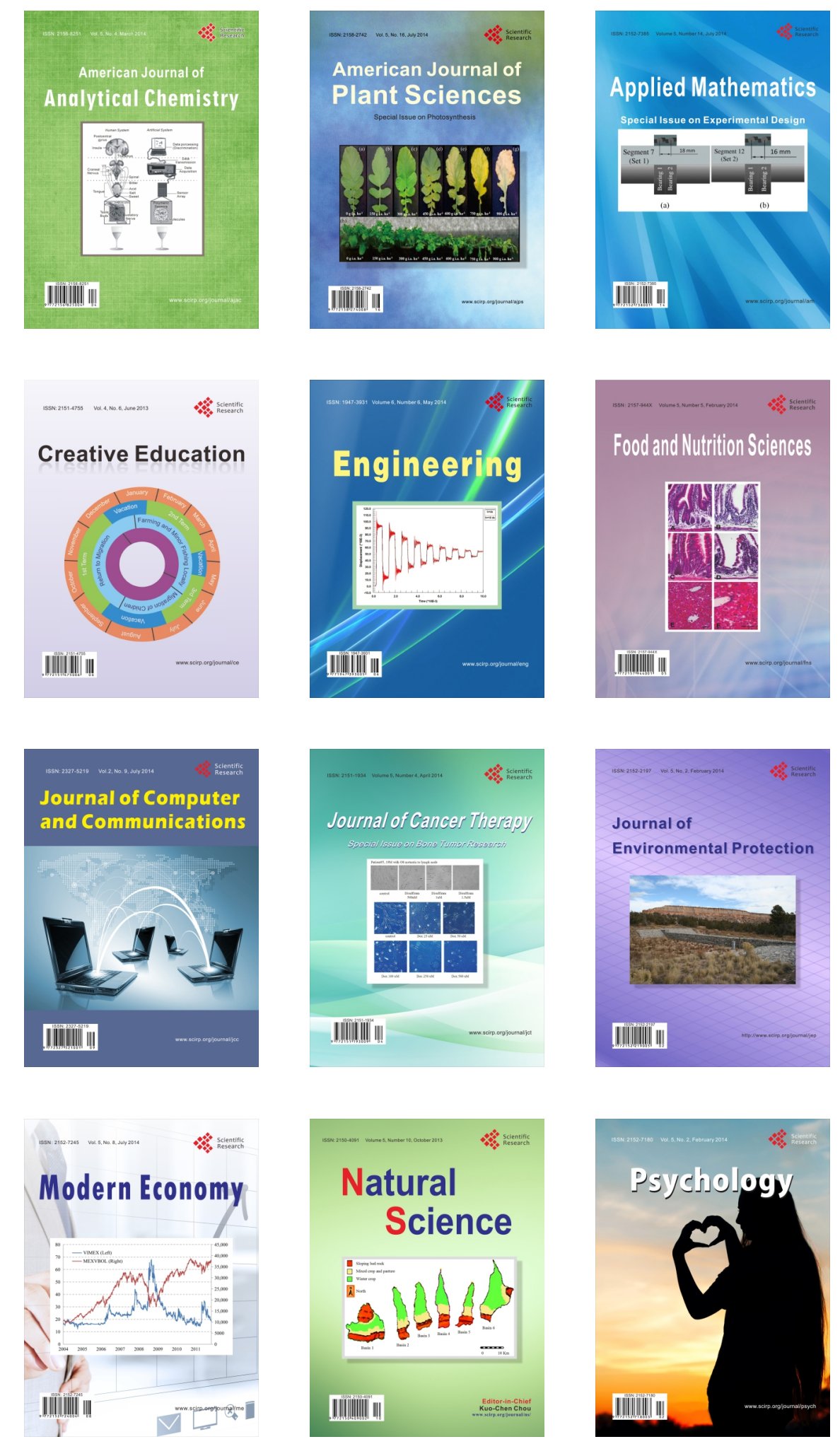